\title{
HDAC inhibitors effectively induce cell type-specific differentiation in human glioblastoma cell lines of different origin
}

\author{
IRINA SVECHNIKOVA ${ }^{1}$, PER M. ALMQVIST ${ }^{2}$ and TOMAS J. EKSTRÖM ${ }^{2}$ \\ ${ }^{1}$ Department of Woman and Child Health, Karolinska Institutet, Pediatric Endocrinology Unit, Q2:08, \\ Karolinska University and Hospital; ${ }^{2}$ Department of Clinical Neuroscience, Karolinska Institutet, \\ Center for Molecular Medicine, Karolinska University and Hospital, L8:01, S-171 76 Stockholm, Sweden
}

Received November 7, 2007; Accepted January 3, 2008

\begin{abstract}
The anti-neoplastic effects of histone deacetylase inhibitors (HDACi), Trichostatin A (TSA) and 4-phenylbutyrate (4-PB) on the human glioblastoma cell lines GBM-29, U-343 MG and U-343 MGa Cl. 2:6 were investigated. TSA and 4-PB induced apoptosis in the three cell lines in a doseand time-dependent manner. Whereas caspase-3 activation was detected in all three cell lines, U-343 MG cells were more sensitive to the apoptotic effect of HDACi compared with U-343 MGa Cl. 2:6. TSA and 4-PB induced differentiation in the three cell lines, each cell line developing unique phenotypic characteristics. During long-term treatment with a low dose of HDACi U-343 MGa Cl. 2:6 cells developed an astrocytic morphology with expression of glial fibrillary acidic protein (GFAP). GFAP-negative U-343 MG cells changed their morphology in response to HDACi and down-regulated their expression of vimentin. The nestin and vimentin positive GBM-29 cells also showed a morphological differentiation, while the expression of the two malignancy markers decreased. In summary, our results showed that these three glioblastoma cell lines display unique phenotypes and differentiation patterns in response to HDACi.
\end{abstract}

\section{Introduction}

Glioblastoma multiforme (GBM) is the most common type of glial tumors with a dismal prognosis despite best standard

Correspondence to: Dr Irina Svechnikova, Department of Woman and Child Health, Karolinska Institutet, Pediatric Endocrinology Unit, Q2:08, Karolinska University and Hospital, S-171 76, Stockholm, Sweden

E-mail: irina.svechnikova@ki.se

Dr Tomas J. Ekström, Department of Clinical Neuroscience, Karolinska Institutet, Center for Molecular Medicine, Karolinska University and Hospital, L8:01, S-171 76, Stockholm, Sweden E-mail: tomas.ekstrom@ki.se

Key words: phenylbutyrate, trichostatin A, glioblastoma, apoptosis, differentiation therapy including surgery, radio- and chemotherapy. The GBM cells are highly anaplastic and heterogeneous, with an ability to migrate along fiber tracts and blood vessels to disseminate in the brain.

Histone deacetylase inhibitors (HDACi) represent a structurally-diverse group of small molecules with proven anti-neoplastic effects in various types of cancer cells inducing growth inhibition, cell differentiation and apoptosis. Two such compounds are 4-phenylbutyrate (4-PB) and Trichostatin A (TSA) which show potent anti-proliferative and differentiating effects on a variety of cancer cells in vitro and in vivo.

4-PB exerts a potent anti-tumor effect in vitro. It was shown to cause growth inhibition and differentiation in various human cancer cells such as colon carcinoma (1), Burkitt's lymphoma (2), primary acute myeloid leukemia (3), retinoblastoma (4), prostate cancer (5), U138 MG, T98G, U373 MG and A-172 glioma cells (6), medulloblastoma (7), hepatocellular carcinoma (8) and others.

Phase I and II clinical trials of 4-PB in refractory solid tumors $(9,10)$ and high-grade astrocytoma (11) have been performed, showing 4-PB to be well tolerated with a benign safety profile. 4-PB has shown efficacy in the treatment of different kinds of tumors, including hormone-refractory prostate cancer (12), hematological malignancy (13), and high grade astrocytoma (14). Several patients in these studies were reported to have stable disease and stable or improved biomarker profiles in response to treatment $(9,11)$. Notably, 4-PB may have an additive or even synergistic effect in combination with conventional anti-cancer drugs such as cytarabine, etoposide, topotecan, doxorubicin $(4,15), 5$ fluorouracil (16), retinoids (17) and the DNA methyltransferase inhibitor 5-azacytidine (18).

4-PB is a short-chain fatty acid known to reversibly inhibit class I and II HDACs. It is considered as an HDAC inhibitor of the first generation, as the HDAC inhibitory effect is not specific. Working concentrations are rather high, in the millimolar range, and the effects are pleiotropic. 4-PB is known to exert multiple effects in the cell, including the modulation of protein isoprenylation, which importantly regulates the ras proto-oncoprotein (19), and activation of the nuclear steroid peroxisome-proliferation-associated receptor 
(PPAR), a transcription factor controlling gene expression and cell phenotype $(11,20)$.

TSA is a reversible selective inhibitor of class I and II HDACs (21-23), which exerts potent antitumor activity in breast cancer (24) in vivo, as well as in vitro in SW620 colon carcinoma cells (25), the T98G glioma cell line and neuroblastoma cells (26). Phase I clinical trials with a compound from the same group of hydroxamic acids, SAHA, have been performed with lymphoma patients and bladder cancer, and have shown objective tumor regression. A clinical response in patients with hematological malignancies has also been reported (27).

The anti-neoplastic mechanism of HDACi is not fully elucidated, but is thought to include the modulation of the chromatin structure by histone acetylation, thereby inducing the transcription of various cell cycle regulating genes (28). This modulation involves an increase in the acetylation of promoter-associated histones. This was shown for the $\mathrm{p} 21^{\text {Wafl }}$ promoter (29), resulting in the loosening of the structure of the chromatin locally and exposure of the regulatory elements to the transcription factors Sp1 and -3 . The chromatin modulation leads to the gene activation of e.g. cell growth inhibitors such as p21 waf1 $(29,30)$; gelsolin, a substrate for caspase-3 (31); p16 $6^{\mathrm{INK} 4 \mathrm{~A}}$ (32); p27 (33); cyclin E (34) and telomerase catalytic subunit TERT (35).

We have previously shown that 4-PB induced apoptosis, differentiation and tumor regression in hepatocellular carcinoma (HCC) and hepatoblastoma tumor xenografts (8). In the present study we showed that HDAC inhibitors 4-PB and TSA induce differentiation and apoptosis in the glioblastoma cell lines GBM-29, U-343 MG and U-343 MGa Cl. 2:6 (U-343 MGa), all of which have a different expression of differentiation markers.

\section{Materials and methods}

Chemicals. Chemicals were of analytical or electrophoretical grade. Phenylbutyrate (4-phenylbutyric acid, sodium salt, 4-PB) was of ultra-pure pharmaceutical grade from Triple Crown America Inc. (PA, USA). Trichostatin A (TSA) was purchased from Sigma-Aldrich Sweden AB, Stockholm, Sweden.

Cell cultures and cell survival assay. The GBM-29 cell line was developed from a tumor explant of glioblastoma multiforme as described (36). The cell lines U-343 MG and MGa Cl. 2:6 were a kind gift from Professor M. Nistér, Karolinska Institutet, Stockholm, Sweden. The cell lines were maintained in Dulbecco's modified Eagle's medium, supplemented with $10 \%$ fetal bovine serum and antibiotics $(100 \mathrm{U} / \mathrm{ml}$ penicillin and $100 \mu \mathrm{g} / \mathrm{ml}$ streptomycin) in an atmosphere of $5 \%$ of $\mathrm{CO}_{2}$.

Cell survival was assessed by the 3-(4,5-dimethylthiazol2-yl)-2,5-diphenyltetrazolium bromide (MTT) assay. The MTT (Sigma) was dissolved in a serum-free culture medium $(0.5 \mathrm{mg} / \mathrm{ml})$, added to the cells $(200 \mu \mathrm{l} / \mathrm{well})$ and incubated for $30 \mathrm{~min}$ at $37^{\circ} \mathrm{C}$. Formazan dye, formed by viable cells, was solubilized in $300 \mu \mathrm{l}$ of isopropanol and aliquots $(100 \mu \mathrm{l})$ were pipetted into 96-well microplates. The absorbance at $570 \mathrm{~nm}$ was measured using an ELISA plate reader.
Cell treatment. The treatment of cells was performed at 50-70\% confluency with 4-PB, 1, 2, 5 and $10 \mathrm{mM}$ dissolved in PBS, or with TSA, 100, 300, 500 and $800 \mathrm{nM}$ dissolved in DMSO. To control the cells, the same amount of solvent was added. The concentration of DMSO did not exceed $0.1 \%$ in the medium.

For analyses of the caspase activity, GBM-29 cells were treated with $5 \mathrm{mM} 4-\mathrm{PB}$ for $18 \mathrm{~h}$ and U-343 MG and MGa cells were treated with $10 \mathrm{mM} 4-\mathrm{PB}$ for $24 \mathrm{~h}$. For the induction of differentiation, U-343 MG cells were treated with 2, 5 and $10 \mathrm{mM}$ of 4-PB or 100,500 and $1000 \mathrm{nM}$ of TSA for 24 and $48 \mathrm{~h}$, or $80 \mathrm{nM}$ of TSA for 14 days. U-343 MGa cells were treated with $100 \mathrm{nM}$ of TSA for 27 days and GBM-29 cells were treated with 5 and $10 \mathrm{mM}$ of 4-PB for $48 \mathrm{~h}$, with $2 \mathrm{mM}$ for 23 days or $100 \mathrm{nM}$ of TSA for 5 days.

Immunocytochemistry. Cells were plated on coverslips and treated with different concentrations of 4-PB or TSA for various times as indicated in the Figures and legends. For immunostaining, GBM-29 cells were washed with PBS, fixed with $4 \%$ paraformaldehyde at room temperature for $20 \mathrm{~min}$, and permeabilized with $0.3 \%$ Triton $\mathrm{X}-100$ for $5 \mathrm{~min}$. Following washing, they were incubated in blocking buffer (0.2\% BSA in TBS, $50 \mathrm{mM}$ Tris-Cl, $\mathrm{pH} 7.4,150 \mathrm{mM} \mathrm{NaCl}$ and $1 \mathrm{mM} \mathrm{CaCl}_{2}$ ) for $20 \mathrm{~min}$ at room temperature. The cells were subsequently incubated overnight at $4{ }^{\circ} \mathrm{C}$ with mouse monoclonal vimentin (Clone Vim 3B4) antibody (1:100, Dako Cytomation, Denmark) and with rabbit polyclonal nestin antiserum (1:100, a kind gift from Dr U. Lendahl, Karolinska Institutet, Stockholm, Sweden) diluted in blocking buffer. The cells were washed with PBS and incubated with Cy-3 conjugated donkey anti-rabbit antibody (1:100, Jackson ImmunoResearch Lab., PA, USA) for $1 \mathrm{~h}$ at room temperature, washed and incubated with rabbit anti-mouse FITCconjugated antibody (1:50, Dako, Denmark). The cells were counterstained with Hoechst 33258 and slides were mounted using Dako fluorescent-mounting medium (Dako Corporation, CA, USA).

U-343 MG cells were stained in a similar manner to that of GBM-29 cells for the detection of vimentin or nestin expression. In another set of experiments, when these cells were stained for vimentin only, secondary AlexaFluor 546 goat anti-mouse antibody (Molecular Probes, Inc., Eugene, Oregon, USA) was used.

For the immunostaining of GFAP, the cells were incubated overnight with $16.4 \mu \mathrm{g} / \mathrm{ml}$ rabbit anti-cow glial fibrillary acidic protein (Dako), which has a strong cross-reaction with the human GFAP, and then with a secondary donkey antirabbit Cy-3 conjugated antibody (1:100, Jackson ImmunoResearch Lab., PA, USA). For the immunostaining of EGFR, the cells were incubated with a rabbit EGFR (1005) antibody (sc-03, Santa Cruz Biotechnology Inc., USA) and donkey antirabbit $\mathrm{Cy}-3$ antibody was used as the secondary antibody.

Western blot analysis. For the immunodetection of vimentin, the cells were scraped in $250 \mu 11 \mathrm{X}$ gel loading buffer $(50 \mathrm{mM}$ Tris-Cl, pH 6.8; $100 \mathrm{mM}$ ditiothreitol, 2\% SDS and 10\% glycerol) and sonicated at $3 \times 10 \mathrm{sec}$. The total protein content was determined by the micro-BCA protein assay (Pierce, IL, USA). Samples of $30 \mu \mathrm{g}$ protein per lane were analysed on a 
10\% PAAG and electrotransferred to a Protran nitrocellulose transfer membrane (Schleicher \& Schuell GmbH, Dassel, Germany). The equal loading of proteins on the Western blots was monitored by staining the membranes with Ponceau S. Immunodetection was done by using mouse monoclonal vimentin antibody, clone Vim 3B4 (1:500, Dako Cytomation) overnight at $4^{\circ} \mathrm{C}$. After washings of nitrocellulose membranes, they were incubated with secondary goat anti-mouse/HRPconjugated antibody (1:2000, Bio-Rad) for $2 \mathrm{~h}$.

For the immunodetection of EGFR, samples of $50 \mu \mathrm{g}$ per lane were analysed on $10 \%$ PAAG and electrotransferred to PVDF-membrane (Millipore, MA, USA). Immunodetection was performed using rabbit EGFR (1005) antibody (sc-03, Santa Cruz Biotechnology Inc.) and secondary anti-rabbit/ HRP-conjugated antibody. After washing, an ECL Plus reaction was performed (Amersham, UK).

A quantification of Western blots was performed, applying Image Gauge Ver.3.11 software (Fuji Photo Film Co., Ltd., Japan).

Caspase-3 activity determination. The determination of caspase-3 was performed as previously described (8), using the ApoAlert caspase fluorescent assay kit (Clontech, CA, USA). Briefly, $1 \times 10^{6}$ cells were harvested and incubated with cell lysis buffer on ice for $10 \mathrm{~min}$ followed by centrifugation. The enzymatic reaction was performed using DEVD-7-amino-4trifluoromethyl coumarin (AFC) as a substrate. The resulting fluorescence was measured at $400 \mathrm{~nm}$ (exitation)/505 nm (emission) on a Perkin Elmer luminescence spectrophotometer LS 50B (Perkin-Elmer Life Sci., Zaventem, Belgium). To verify the specificity of the enzymatic reactions, the specific inhibitor of caspase-3, DEVD-CHO was used. The specific activity of caspase-3 was expressed as the amount of released AFC per hour [ $\mu$ mole of $\mathrm{AFC} /(\mathrm{h} \mathrm{x} \mathrm{g} \mathrm{protein)].}$

Statistical analysis. Statistical analysis was performed using Student's t-test and SigmaPlot 9.0s software (Systat Software GmbH, Erkrath, Germany).

\section{Results}

Characteristics of the glioblastoma cell lines. GBM-29, U-343 MG and MGa cell lines were established from surgical specimens of glioblastoma multiforme tumors, the latter two cell lines being derived from the same tumor specimen (37). Cell morphology and the expression of differentiation markers differ between cell lines (Table I, Fig. 1). In culture conditions promoting cell proliferation, U-343 MGa cells are polygonal without processes, and express the astrocytespecific intermediate-filament differentiation marker, glial fibrillary acidic protein (GFAP). In contrast, the U-343 MG cells exhibit a fibro/fascicular morphology with expression of vimentin, an intermediate filament of the neural precursor and mesenchymal cells. Unlike U-343 MG and MGa, GBM-29 cells express high levels of the intermediate filament protein nestin as well as vimentin, a characteristic of neuro-epithelial precursor cells (38). The GBM-29 cell morphology resembles that of U-343 MG, but unlike U-343 MG, they grow very slowly, are sparsely distributed and never reach the same density as the other two types of glioblastoma cell lines.
Table I. Expression of the differentiation markers in glioblastoma cell lines.

\begin{tabular}{lccc}
\hline Cell line & GBM-29 & U-343 MG & U-343 MGa Cl 2:6 \\
\hline GFAP & $-^{\mathrm{a}}$ & $-^{\mathrm{a}, \mathrm{b}}$ & $+++^{\mathrm{a}, \mathrm{b}}$ \\
Fibronectin & n.d. & $+^{\mathrm{b}}$ & $-^{\mathrm{b}}$ \\
Nestin & $+^{\mathrm{a}}$ & $-^{\mathrm{a}}$ & $+^{\mathrm{a}}$ \\
Vimentin & $+^{\mathrm{a}}$ & $+^{\mathrm{a}, \mathrm{b}}$ & $+^{\mathrm{a}, \mathrm{b}}$ \\
EGFR & $+^{\mathrm{a}}$ & $-^{\mathrm{a}}$ & $+^{\mathrm{a}, \mathrm{c}}$
\end{tabular}

-, not detected; +, expressed; +++, highly expressed; n.d., not determined; athe data of this study; bthe data were obtained from (37) and cthe data were obtained from (48).

The expression of another marker protein, the EGF receptor (EGFR), was found in GBM-29 and U-343 MGa cells, but not in U-343 MG (Table I).

The anti-proliferative effect of 4-PB and TSA on glioblastoma cells. 4-PB and TSA showed time- and dose-dependent antiproliferative and pro-apoptotic effects on all glioblastoma cell lines tested, although the sensitivity of the cell lines to HDACi differed (Fig. 2). In the GBM-29 cells, an anti-proliferative effect of 4-PB was detected at $1 \mathrm{mM}$ concentration after 3 days of treatment $(\mathrm{P}<0.01$, Fig. $2 \mathrm{~A})$. At $5 \mathrm{mM}$ of $4-\mathrm{PB}, \sim 50 \%$ of the cells were dead after 4 days of treatment. Similarly, TSA induced growth inhibition starting at a $100 \mathrm{nM}$ concentration at $24 \mathrm{~h}$ of treatment $(\mathrm{P}<0.01$, Fig. $2 \mathrm{~B})$.

U-343 MG cells were also sensitive to 4-PB treatment (Fig. 2C) with an $\mathrm{IC}_{50}$ of $10 \mathrm{mM}$ after 2 days of treatment. They were more sensitive to TSA treatment than GBM-29 cells, a $100 \mathrm{nM}$ concentration killed all cells after 5 days of treatment (Fig. 2D). Unlike the GBM-29 and U-343 MG cell lines, U-343 MGa cells were quite resistant to 4-PB treatment. $\mathrm{IC}_{50}$ for $4-\mathrm{PB}$ at 4 days was almost twice as high as that for GBM-29 and U-343 MG cells (8 mM) (Fig. 2E). U-343 MGa cells were also more resistant to TSA than U-343 MG cells, with $70 \%$ of the cells being viable at 5 days of treatment with $100 \mathrm{nM}$ concentration, and $50 \%$ after two days of treatment with $300 \mathrm{nM}$ (Fig. 2F).

Phenylbutyrate induces apoptosis in glioblastoma cell lines. 4-PB induced apoptosis in the three glioblastoma cell lines tested, as analysed by the caspase- 3 activity. The treatment of GBM-29 cells with 4-PB at $5 \mathrm{mM}$ for $18 \mathrm{~h}$ resulted in a 3.5-fold elevation of caspase- 3 activity versus the untreated control cells (Fig. 3A). The caspase-3 specific inhibitor DEVK-CHO inhibited this activity by $75 \%$. In the U-343 MG cells, caspase- 3 activity increased by 2.7 -fold with the same treatment (Fig. 3B), while $10 \mathrm{mM} 4-\mathrm{PB}$ increased the caspase-3 activity 1.5-fold in U-343 MGa cells (Fig. 3C).

Cell differentiation in response to the HDAC inhibitors. The three cell lines differentiated in response to 4-PB or TSA. In the U-343 MGa cells, $100 \mathrm{nM}$ TSA treatment for four weeks resulted in an astrocyte-like differentiation of a subset of cells with a high expression of GFAP and characteristic morphology 

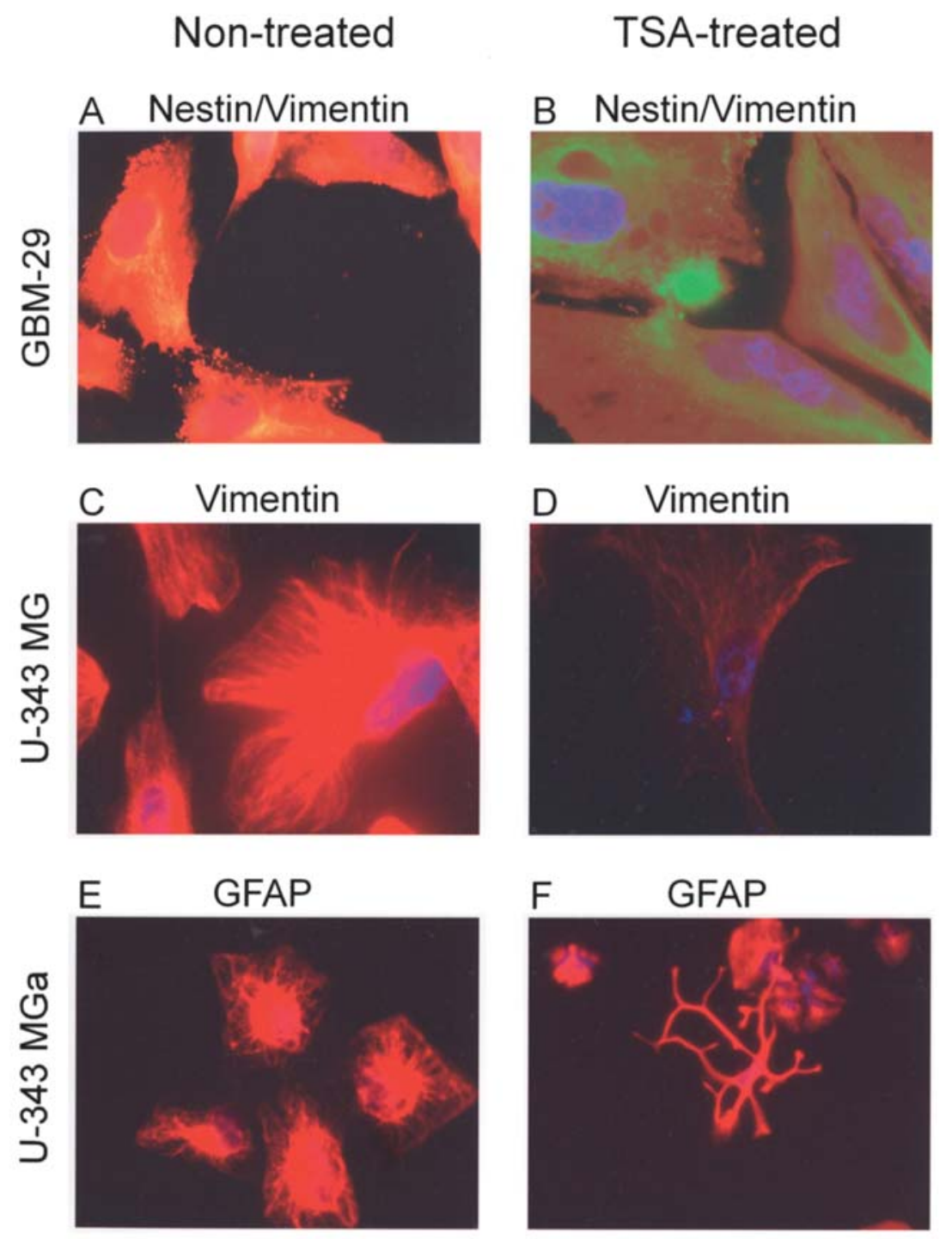

Figure 1. Differentiation effect of HDACi in the different glioblastoma cell lines: GBM-29 (A and B), U-343 MG (C and D) and U-343 MGa Cl. 2:6 (E and F), untreated (A, C and E) or treated with TSA (B, D and F). GBM-29 cells were treated with $100 \mathrm{nM}$ TSA for 5 days and stained for the differentiation markers of nestin (red) and vimentin (green) expression. U-343 MG cells were treated with $80 \mathrm{nM}$ TSA for 14 days and stained for vimentin expression (red). U-343 MGa Cl. 2:6 cells were treated with $100 \mathrm{nM}$ TSA for 27 days and stained for GFAP expression to show the morphological response to treatment with TSA. Note the change of cell morphology from polygonal to multipolar. Immunostaining was performed as indicated in Materials and methods.

(Fig. 1F). Prolongation of the treatment brought even more cells to differentiation. Similarly, the treatment of these cells with $1 \mathrm{mM}$ 4-PB for 13 days induced astrocytic differentiation (data not shown). Glioblastoma cells resembled mature astrocytes with strong GFAP immunostaining.

The treatment of GBM-29 cells with either of the two HDACi resulted in a decreased nestin and vimentin expression. Treatment with $100 \mathrm{nM}$ TSA for 5 days decreased the nestin expression considerably (compare Fig. 1A and B). High doses of $4-\mathrm{PB}(5$ and $10 \mathrm{mM}$ ) for $48 \mathrm{~h}$ resulted in a 25 and $44 \%$ reduction of the vimentin expression, respectively (Fig. 4A). A low dose of 4-PB $(2 \mathrm{mM})$ resulted in a $30 \%$ reduction of the vimentin expression, after 6 days of treatment and a $70 \%$ reduction after 23 days of treatment (data not shown).

U-343 MG cells were less responsive to 4-PB and TSA than GBM-29. 4-PB at $10 \mathrm{mM}$ reduced the vimentin expression by $\sim 30 \%$ after $48 \mathrm{~h}$ of treatment (Fig. $4 \mathrm{~B}$ ). TSA decreased the vimentin expression in a dose- and time- dependent manner (Fig. 4B, compare also Fig. 1C and D). A reduction by $23-27 \%$ after $24 \mathrm{~h}$ of treatment was seen at concentrations of TSA 500 and $1000 \mathrm{nM}$ and by 60 and $80 \%$ after $48 \mathrm{~h}$ of treatment with the same concentrations of TSA, respectively.

\section{Discussion}

It is well established that HDAC inhibitors exert differentiation effects on many types of cancer cells, including hepatocellular carcinoma $(8,39,40)$, breast cancer $(39)$ and human prostate cancer cells (41). Herein we demonstrated that the HDAC inhibitors 4-PB and TSA possess growth-inhibitory, unique differentiation and pro-apoptotic effects on human glioblastoma cell lines of different cellular origin. We previously showed that 4-PB exerts anti-proliferative, apoptotic and differentiating effects on hepatoblastoma and HCC in vivo and in vitro (8), where the expression of the malignancy marker, $\alpha$-fetoprotein, 
4-PB treated

A GBM-29

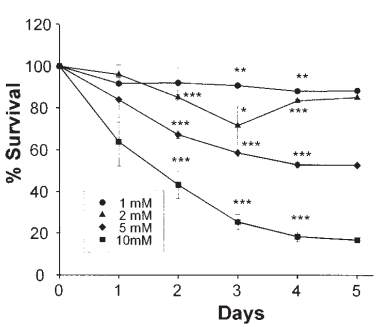

C U-343 MG
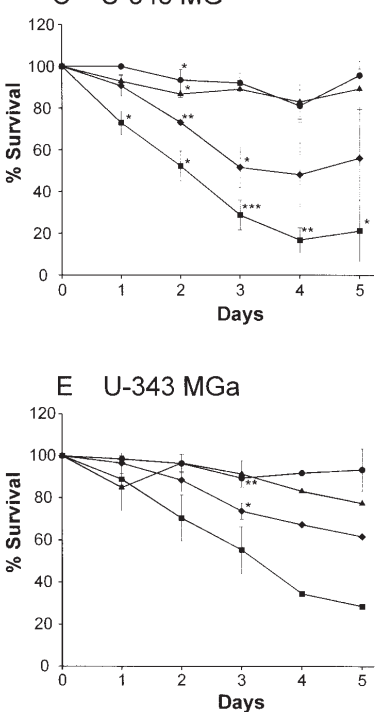

E U-343 MGa
TSA treated

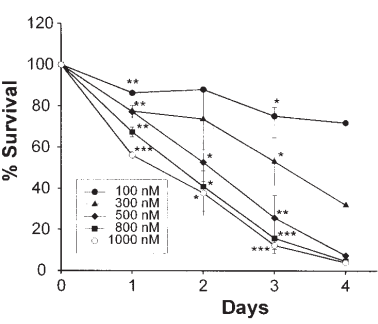

D U-343 MG

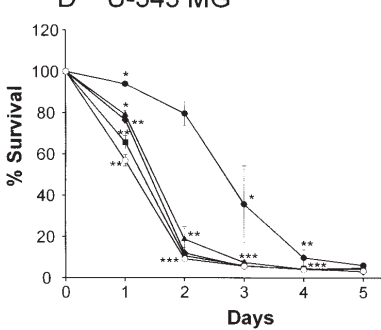

F U-343 MGa

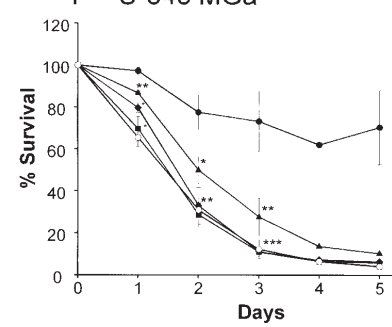

B GBM-29

Figure 2. Reduced survival of glioblastoma cell lines GBM-29, U-343 MG and $\mathrm{MGa} \mathrm{Cl}$. 2:6 after treatment with increasing concentrations of HDAC inhibitors 4-PB (A, C and E) and TSA (B, D and F) over 5 days. Cell survival was analysed by the MTT-test in quadruplicate. At least two independent experiments for each treatment were performed. The results presented are the mean values \pm SEM and are expressed as a percentage of the survival of the control cells. ${ }^{*} \mathrm{P}<0.05,{ }^{* *} \mathrm{P}<0.01$ and ${ }^{* * *} \mathrm{P}<0.001$ when compared to the control cells.

was reduced in $\mathrm{HCC}$ under 4-PB treatment in a way that could be considered as a sign of differentiation.

Results from MTT tests clearly showed that the viability of the studied cell lines was decreased significantly by treatment with HDACi in a time- and dose-dependent manner. The U-343 MG cells of mesenchymal origin, were more sensitive to the differentiating influence of HDACi than the neuroepithelial U-343 MGa cells. The mechanism for the different sensitivity of these cell lines to HDACi is unclear, but is probably derived from unique epigenetic properties that separate the two cell types from one another.

The mechanism of the reduction in viability is an increase in apoptosis. As was shown before by the TUNEL assay in hepatocarcinoma and hepatoblastoma, the amount of apoptotic cells increased significantly after 4-PB treatment. An analysis of the caspase- 3 activity, the effector caspase of apoptosis, also showed an increase after 4-PB treatment (8). In this investigation we also found caspase- 3 activation by 4-PB in GBM-29, U-343 MG and MGa cells. Thus, the HDAC inhibitors induce apoptosis in these glioblastoma cell lines.

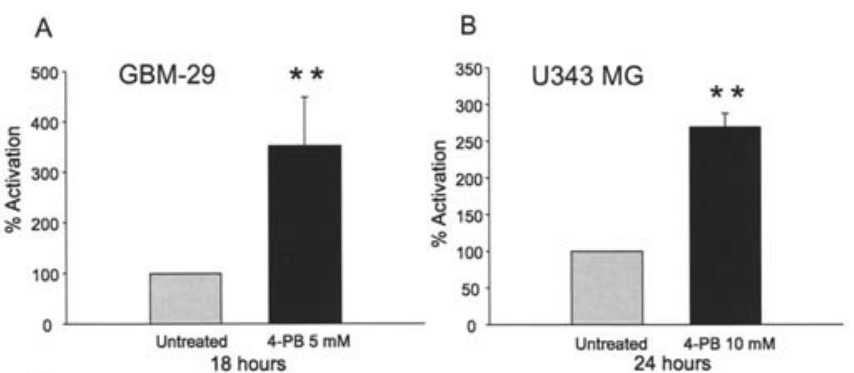

C

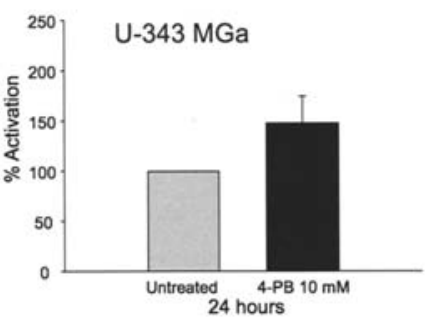

Figure 3. The relative activity of caspase-3 in cell lysates of glioblastoma cell lines GBM-29 (A), U-343 MG (B) and U-343 MGa Cl. 2:6 (C), treated with 4-PB. The specific activity of caspase-3 against DEVD-AFC was measured in duplicate and presented as a percentage of the activity in the control cells. The results presented are the mean values \pm SEM from two independent experiments. ${ }^{* *} \mathrm{P}<0.01$ when compared to the control cells.
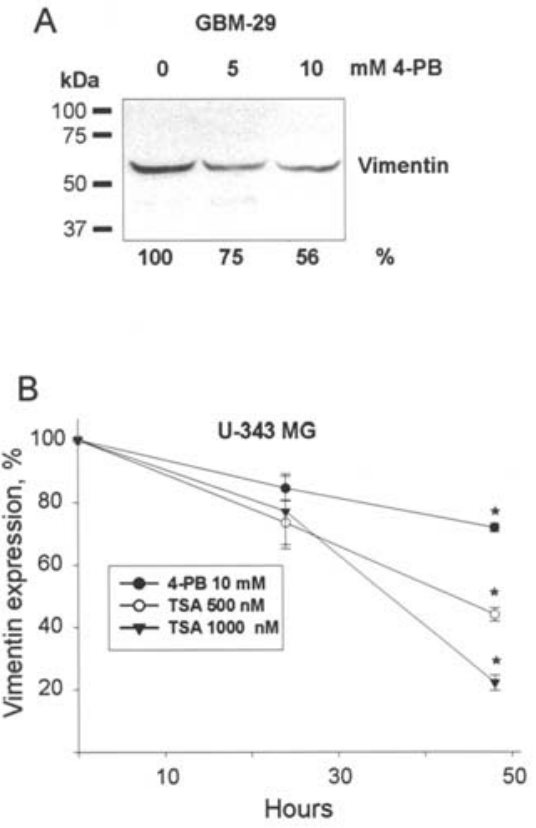

Figure 4. The western blot analysis of the vimentin expression by GBM-29 cells in response to treatment with 4-PB for $48 \mathrm{~h}(\mathrm{~A})$ and by U-343 MG cells, treated with $10 \mathrm{mM} 4-\mathrm{PB}, 500$ or $1000 \mathrm{nM}$ TSA for $24-48 \mathrm{~h}(\mathrm{~B})$. The data presented are values of the densitometric analysis of a representative Western blot of three independent experiments (A) and means \pm SEM for three independent experiments (B) as a percentage from the control cells. ${ }^{*} \mathrm{P}<0.05$ when compared to the control cells.

The differentiation effect of HDAC inhibitors is prominent and can be visualized by morphological changes of the glioblastoma cell lines, and changes in the expression of marker 
proteins. The differentiation effect by 4-PB was previously shown in U138 MG, T98G, U373 MG and A-172 human glioblastoma cell lines (42). They respond quickly (within $72 \mathrm{~h}$ ) with the retraction of cell borders and extension of long cytoplasmic processes, making the appearance astrocyte-like. In our experiments, long-term treatment was needed to induce cell differentiation. After four weeks of treatment with HDACi, U-343 MGa cells acquired astrocyte-like morphology with long, slender cytoplasmic processes and dichotomic branching and strong GFAP immunoreactivity.

Despite the primitive, polygonal morphology, U-343 MGa cells expressed high levels of GFAP in their native state. Treatment with the HDAC inhibitor TSA did not affect the expression of this protein, presumably since the gene was already in a transcriptionally active state, and not a target for HDAC inhibition. However, the cell morphology became more mature and astrocyte-like, following long-term treatment (four weeks) with low doses of 4-PB or TSA (Fig. 1F).

U-343 MG cells were also differentiated under the influence of HDAC inhibitors, but along a different pathway. Native, untreated U-343 MG cells expressed vimentin, while they were devoid of GFAP. Vimentin is a differentiation marker of mesenchymal and neuro-ectodermal cells, and is expressed prior to other type III intermediate filament proteins. During the differentiation and development of the neural cells and muscle, it is replaced by GFAP and desmin, respectively (43). An increased vimentin expression appears to enhance the malignancy of certain tumor types (44). Thus, a reduction in the vimentin expression and reversion of the undifferentiated phenotype of the tumor cells may be considered as a sign of reduced malignancy.

Malignant cells with a GFAP-/fibronectin ${ }^{+}$phenotype are relatively common among cell lines derived from glioma explants (45). They may represent a subpopulation of cells, which exist in original GBM tumors in vivo. These cells are not derived from non-neoplastic mesenchymal cells and give rise to permanent tumorigenic cell lines with abnormal karyotypes (45).

The GBM-29 cells, established from a glioblastoma multiforme explant (36), differ substantially from the other glioblastoma cell lines tested. Unlike U-343 MGa, GBM-29 is GFAP-negative. GBM-29 cells express vimentin and nestin, the latter being a marker of neuro-epithelial stem cells (38), and are of neuro-epithelial origin. Similar cells have been described in anaplastic gliomas (46). GBM-29 cell treatment with HDACi reduced the nestin expression considerably, which is a sign of the transit of the cells from a malignant to a more benign phenotype.

The EGF receptor expression was found in GBM-29 and U-343 MGa cells, but not in U-343 MG (Table I). The EGF receptor (EGFR) is a marker protein expressed in neuroepithelial and glioma cells. In most humans, the malignant glioma c-erbB/EGFR gene is amplified (47).

Thus, the cells of different origin and expressing different markers can be present in glioblastomas. This presumably contributes to the high resistance of the tumors to standard cancer therapy. However, irrespective of the origin of the three glioblastoma cell lines studied, all of them responded to the apoptotic and differentiating effect of HDACi. The cells of a neuroglial nature (U-343 MGa) differentiated into GFAP- expressing astrocyte-like cells. The cells of a mesenchymal nature (U-343 MG) or neuro-epithelial cells (GBM-29) decreased their expression of vimentin and nestin and acquired signs of cellular maturation and differentiation.

In summary, the HDAC inhibitors 4-PB and TSA promote cell differentiation in glioblastoma cell lines of different origin. However, each cell line showed a specific differentiation pattern, including a unique cell morphology and the expression of differentiation markers. The results obtained may have pronounced diagnostic and prognostic values when using HDACi as differentiating agents for the therapy of glioblastoma multiforme.

\section{Acknowledgements}

This work was supported by the Swedish Cancer Foundation, the Swedish Children Cancer Foundation, and funds from Karolinska Institutet. We thank Professor Monica Nistér for the glioblastoma cell lines used in this study, and for useful discussions.

\section{References}

1. Huang Y and Waxman S: Enhanced growth inhibition and differentiation of fluorodeoxyuridine-treated human colon carcinoma cells by phenylbutyrate. Clin Cancer Res 4: 2503-2509, 1998.

2. Bar-Ner M, Thibault A, Tsokos M, Magrath IT and Samid D: Phenylbutyrate induces cell differentiation and modulates Epstein-Barr virus gene expression in Burkitt's lymphoma cells. Clin Cancer Res 5: 1509-1516, 1999.

3. Gore SD, Samid D and Weng LJ: Impact of the putative differentiating agents sodium phenylbutyrate and sodium phenylacetate on proliferation, differentiation, and apoptosis of primary neoplastic myeloid cells. Clin Cancer Res 3: 1755-1762, 1997.

4. Calvaruso G, Carabillo M, Giuliano M, et al: Sodium phenylbutyrate induces apoptosis in human retinoblastoma Y79 cells: the effect of combined treatment with the topoisomerase I-inhibitor topotecan. Int J Oncol 18: 1233-1237, 2001

5. Melchior SW, Brown LG, Figg WD, et al: Effects of phenylbutyrate on proliferation and apoptosis in human prostate cancer cells in vitro and in vivo. Int J Oncol 14: 501-508, 1999.

6. Engelhard HH, Homer RJ, Duncan HA and Rozental J: Inhibitory effects of phenylbutyrate on the proliferation, morphology, migration and invasiveness of malignant glioma cells. J Neurooncol 37: 97-108, 1998.

7. Li XN, Parikh S, Shu Q, et al: Phenylbutyrate and phenylacetate induce differentiation and inhibit proliferation of human medulloblastoma cells. Clin Cancer Res 10: 1150-1159, 2004.

8. Svechnikova I, Gray SG, Kundrotiene J, Ponthan F, Kogner P and Ekström TJ: Apoptosis and tumor remission in liver tumor xenografts by 4-phenylbutyrate. Int J Oncol 22: 579-588, 2003.

9. Gilbert J, Baker SD, Bowling MK, et al: A phase I dose escalation and bioavailability study of oral sodium phenylbutyrate in patients with refractory solid tumor malignancies. Clin Cancer Res 7: 2292-2300, 2001.

10. Carducci MA, Gilbert J, Bowling MK, et al: A Phase I clinical and pharmacological evaluation of sodium phenylbutyrate on a 120-h infusion schedule. Clin Cancer Res 7: 3047-3055, 2001.

11. Gore SD and Carducci MA: Modifying histones to tame cancer: Clinical development of sodium phenylbutyrate and other histone deacetylase inhibitors. Expert Opin Investig Drugs 9: 2923-2934, 2000.

12. Bowling MK, Nelson JB, Tong KP, et al: Biomarker response in men with advanced prostate cancer (PCA) to infusional phenylbutyrate (PB). Proc Am Soc Clin Oncol 15: A43, 1996.

13. Gore SD, Miller CB, Weng LJ, et al: Clinical development of sodium phenylbutyrate (SPB) as a putative differentiating agent in myeloid malignancies. Anticancer Res 17: 3938, 1997.

14. Fisher JD, Carducci MA, Baker SD, et al: Dose escalation study of oral sodium phenylbutyrate $(\mathrm{PB})$ in patients with refractory high grade astrocytomas: maximum tolerated dose, toxicity profile, pharmacology and survival. Proc Am Soc Clin Oncol 19: $166 a, 2000$. 
15. Witzig TE, Timm M, Stenson M, Svingen PA and Kaufmann SH: Induction of apoptosis in malignant B cells by phenylbutyrate or phenylacetate in combination with chemotherapeutic agents. Clin Cancer Res 6: 681-692, 2000.

16. Sung MW and Waxman S: Chemodifferentiation therapy with fluorouracil and phenylbutyrate in advanced colorectal cancer: a Phase I trial. Proc Am Assoc Cancer Res 40: 339, 1999.

17. Pili R, Kruszewski MP, Hager BW, Lantz J and Carducci MA: Combination of phenylbutyrate and 13-cis retinoic acid inhibits prostate tumor growth and angiogenesis. Cancer Res 61: 1477-1485, 2001.

18. Cameron EE, Bachman KE, Myohanen S, Herman JG and Baylin SB: Synergy of demethylation and histone deacetylase inhibition in the re-expression of genes silenced in cancer. Nat Genet 21: 103-107, 1999.

19. Samid D, Ram Z, Hudgins WR, et al: Selective activity of phenylacetate against malignant gliomas: resemblance to fetal brain damage in phenylketonuria. Cancer Res 54: 891-895, 1994.

20. Pineau T, Hudgins WR, Liu L, et al: Activation of a human peroxisome proliferator-activated receptor by the antitumor agent phenylacetate and its analogs. Biochem Pharmacol 52: 659-667, 1996.

21. Yoshida M, Kijima M, Akita M and Beppu T: Potent and specific inhibition of mammalian histone deacetylase both in vivo and in vitro by trichostatin A. J Biol Chem 265: 17174-17179, 1990.

22. Marks P, Rifkind RA, Richon VM, Breslow R, Miller T and Kelly WK: Histone deacetylases and cancer: causes and therapies. Nat Rev Cancer 1: 194-202, 2001.

23. Gray SG and Ekstrom TJ: The human histone deacetylase family. Exp Cell Res 262: 75-83, 2001.

24. Vigushin DM, Ali S, Pace PE, et al: Trichostatin A is a histone deacetylase inhibitor with potent antitumor activity against breast cancer in vivo. Clin Cancer Res 7: 971-976, 2001.

25. Chen Z, Clark S, Birkeland M, et al: Induction and superinduction of growth arrest and DNA damage gene 45 (GADD45) alpha and beta messenger RNAs by histone deacetylase inhibitors trichostatin A (TSA) and butyrate in SW620 human colon carcinoma cells. Cancer Lett 188: 127-140, 2002.

26. Wang ZM, Hu J, Zhou D, Xu ZY, Panasci LC and Chen ZP: Trichostatin A inhibits proliferation and induces expression of p21WAF and p27 in human brain tumor cell lines. Aizheng 21: 1100-1105, 2002.

27. Kelly WK, Richon VM, O'Connor O, et al: Phase I clinical trial of histone deacetylase inhibitor: suberoylanilide hydroxamic acid administered intravenously. Clin Cancer Res 9: 3578-3588, 2003.

28. Yoshida M, Furumai R, Nishiyama M, Komatsu Y, Nishino N and Horinouchi S: Histone deacetylase as a new target for cancer chemotherapy. Cancer Chemother Pharmacol 48: S20-S26, 2001.

29. Gui CY, Ngo L, Xu WS, Richon VM and Marks PA: Histone deacetylase (HDAC) inhibitor activation of p21WAF1 involves changes in promoter-associated proteins, including HDAC1. Proc Natl Acad Sci USA 101: 1241-1246, 2004.

30. Archer SY, Meng S, Shei A and Hodin RA: p21(WAF1) is required for butyrate-mediated growth inhibition of human colon cancer cells. Proc Natl Acad Sci USA 95: 6791-6796, 1998.

31. Hoshikawa Y, Kwon HJ, Yoshida M, Horinouchi S and Beppu T: Trichostatin A induces morphological changes and gelsolin expression by inhibiting histone deacetylase in human carcinoma cell lines. Exp Cell Res 214: 189-197, 1994.
32. Munro J, Barr NI, Ireland H, Morrison V and Parkinson EK: Histone deacetylase inhibitors induce a senescence-like state in human cells by a p16-dependent mechanism that is independent of a mitotic clock. Exp Cell Res 295: 525-538, 2004.

33. Gray SG, Eriksson T and Ekstrom TJ: Methylation, gene expression and the chromatin connection in cancer (review). Int J Mol Med 4: 333-350, 1999.

34. Sambucetti LC, Fischer DD, Zabludoff S, et al: Histone deacetylase inhibition selectively alters the activity and expression of cell cycle proteins leading to specific chromatin acetylation and antiproliferative effects. J Biol Chem 274: 34940-34947, 1999.

35. Takakura M, Kyo S, Sowa Y, et al: Telomerase activation by histone deacetylase inhibitor in normal cells. Nucleic Acids Res 29: 3006-3011, 2001

36. Asklund T, Appelskog IB, Ammerpohl O, et al: Gap junctionmediated bystander effect in primary cultures of human malignant gliomas with recombinant expression of the HSVtk gene. Exp Cell Res 284: 185-195, 2003.

37. Enblad P, Hesselager G, Bongcam-Rudloff E, Hallin I, Westermark B and Nister M: Modulation of phenotype and induction of irregular vessels accompany high tumorigenic potential of clonal human glioma cells xenografted to nude-rat brain. Int J Cancer 85: 819-828, 2000.

38. Lendahl U, Zimmerman LB and McKay RD: CNS stem cells express a new class of intermediate filament protein. Cell 60: $585-595,1990$.

39. Tsubaki J, Choi WK, Ingermann AR, et al: Effects of sodium butyrate on expression of members of the IGF-binding protein superfamily in human mammary epithelial cells. J Endocrinol 169: 97-110, 2001.

40. Yamamoto H, Fujimoto J, Okamoto E, Furuyama J, Tamaoki T and Hashimoto-Tamaoki T: Suppression of growth of hepatocellular carcinoma by sodium butyrate in vitro and in vivo. Int $\mathrm{J}$ Cancer 76: 897-902, 1998.

41. Carducci MA, Nelson JB, Chan-Tack KM, et al: Phenylbutyrate induces apoptosis in human prostate cancer and is more potent than phenylacetate. Clin Cancer Res 2: 379-387, 1996.

42. Engelhard HH, Duncan HA and Dal Canto M: Molecular characterization of glioblastoma cell differentiation. Neurosurgery 41: 886-897, 1997.

43. Paramio JM and Jorcano JL: Beyond structure: do intermediate filaments modulate cell signalling? Bioessays 24: 836-844, 2002.

44. Hendrix MJ, Seftor EA, Chu YW, Trevor KT and Seftor RE: Role of intermediate filaments in migration, invasion and metastasis. Cancer Metastasis Rev 15: 507-525, 1996.

45. Nister M and Westermark B: Human glioma cells. In: Atlas of Human Tumor Cell Lines. Hay RJ, Park JG and Gazdar A (eds). Academic Press Inc., New York, pp17-42, 1994.

46. Almqvist PM, Mah R, Lendahl U, Jacobsson B and Hendson G: Immunohistochemical detection of nestin in pediatric brain tumors. J Histochem Cytochem 50: 147-158, 2002.

47. Libermann TA, Nusbaum HR, Razon N, et al: Amplification, enhanced expression and possible rearrangement of EGF receptor gene in primary human brain tumours of glial origin. Nature 313: 144-147, 1985.

48. Westermark B, Magnusson A and Heldin CH: Effect of epidermal growth factor on membrane motility and cell locomotion in cultures of human clonal glioma cells. J Neurosci Res 8: 491-507, 1982. 